\title{
Communitywide strategies key to preventing childhood obesity
}

\author{
by Patricia B. Crawford, Constance L. \\ Schneider, Anna C. Martin, Theresa Spezzano, \\ Susan Algert, Chutima Ganthavorn, Yvonne \\ Nicholson, Marisa Neelon, Patti C. Wooten \\ Swanson and Susan Donohue
}

\section{Approximately 25 million children in} the United States are obese or at risk of becoming obese, with anticipated negative consequences for individual health as well as the nation's future health-care costs. Effective interventions to prevent obesity require more than educating individuals. To bring about change, we must deploy tactics at multiple levels, from community facilities like parks and bike paths to foods offered in schools. The Spectrum of Prevention proposed in 1999 by L. Cohen and S. Smith first described this approach. UC Cooperative Extension (UCCE) has helped evaluate large-scale community-based obesity prevention programs and has experience aligning county nutrition programs with new dietary guidelines. This UCCE expertise enables UC to develop more effective obesity prevention strategies and to influence policy addressing childhood obesity. Notably, UCCE's expertise in nutrition and obesity prevention will be applied to implementing a new intervention program. The new program employs multiple components including UC Cooperative Extension materials and community networks and is designed to impact factors contributing to risk for childhood obesity.

\footnotetext{
7 he rise in obesity in the United States 1 is a severe health crisis that is undermining our well-being, economic competitiveness and even our national security (Glickman, Leavitt et al. 2012). Two-thirds of Americans are either overweight or obese, and the number of obese adults has doubled over the last 30 years. Even
}

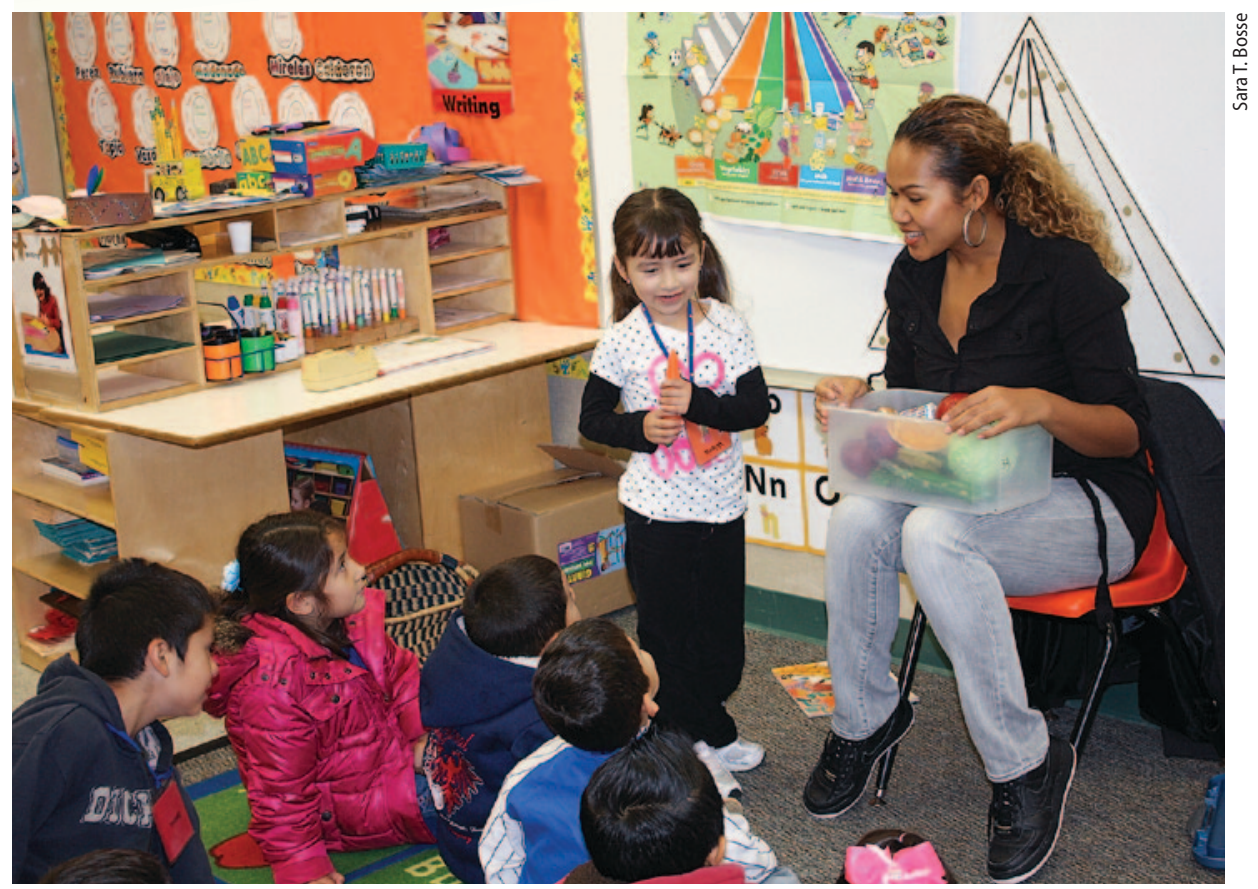

Schools, where students eat one or two meals each weekday, are prime areas for reducing obesity risk. After participating in the UC CalFresh Nutrition Education Program, low-income youth in Fresno County improved their fruit and vegetable intake and increased physical activity. Above, CalFresh educator Nath Say explains the importance of eating a variety of fresh produce.

\section{Most Americans continue to believe that weight is an issue linked almost exclusively to personal responsibility, and this view is a serious obstacle in the fight against obesity (Quinlan et al. 2010).}

more troubling, the prevalence of obesity among children has tripled. From 1980 to 2010 , obesity increased from $6.5 \%$ to $18.0 \%$ among 6- to 11-year-olds and from 5.0\% to $18.4 \%$ among adolescents aged 12 to 19 (Ogden et al. 2012).

Currently, 25 million children in the United States are obese or overweight (Ogden et al. 2010). These youth are at increased risk for a variety of medical conditions that have lifelong consequences. One-sixth of all school-aged obese children are already experiencing heart disease risk factors, including high blood pressure and lipid disorders (Berenson 2005). In addition, it is now projected that one-third of the children born in this decade will develop type 2 diabetes in their lifetime and that our current generation of youth will have a shorter life span than their parents if we are not able to reduce the current rates of obesity in the United States (Olshansky et al. 2005).
These outcomes could be economically devastating for the U.S. medical care system, which will face the extraordinary expense of caring for vastly increased numbers of people suffering from chronic weight-related conditions. The current annual cost of obesity-related conditions in the United States is $\$ 147$ billion for direct medical care (Finkelstein et al. 2009), and these costs are projected to double every decade if obesity rates are not curbed (Wang et al. 2008).

\section{Preventing obesity}

The primary cause of obesity is energy imbalance - too many calories consumed and too few calories burned. While the medical approach to combating

Online: http://californiaagriculture.ucanr.edu/ landingpage.cfm?article =ca.v067n01p13\&fulltext=yes DOI: 10.3733/ca.v067n01p13 
child obesity is oriented toward treating individuals, populationwide prevention may be a more effective and economical approach (Fisberg et al. 2004; Swinburn et al. 2005). Prevention efforts have the benefit of promoting healthy lifestyles for children of all weights, are less resource intensive than individual remediation and avoid the difficulty of case identifica- acknowledge that it is likely that environmental factors have contributed to the rapid rise in obesity, since human genetics cannot have changed in the brief period of the last 30 years. Indeed, it has been suggested that the community environment has a greater impact on individual health than genetic background or use of the health-care system (Cubbin et al. 2008).

\section{... recent comprehensive school and community interventions are beginning to decrease children's body mass indices (BMIs) ...}

tion and the expense of intensive longterm counseling (Kumanyika et al. 2002). Further, individually oriented treatment can be damaging to children's self-esteem and psychological well-being (Zametkin et al. 2004). Moreover, efforts to prevent obesity may offer more promise for children than for adults, since youth have not had as many years to establish healthrelated behaviors that contribute to excessive weight gain (Fisberg et al. 2004).

To identify strategies for obesity prevention - ways to limit excess caloric intake or encourage adequate physical activity - population behaviors that may contribute to the rise in obesity have been looked at by expert panels convened by the Centers for Disease Control and Prevention (CDC), U.S. Department of Health and Human Services, U.S. Department of Agriculture, American Institute for Cancer Research and World Health Organization (WHO) (Kumanyika et al. 2002). In recommending obesity prevention strategies, these expert panels
Therefore, to reverse the current obesity crisis, we must create environments that support health (Parker et al. 2009). In other words, to enable individual children to make healthy choices, we must focus on changing the communities where they live and go to school in order to provide an environment that makes healthful choices possible.

\section{Local obesity prevention}

The highest childhood obesity prevalence is among low-income groups as well as racial/ethnic groups including African Americans, Latinos and Native Americans (Madsen et al. 2010). Many of the factors that contribute to obesity are exacerbated in low-income communities, where healthy and affordable food options and safe opportunities for physical activity are lacking (Samuels et al. 2010). Individuals' behavior choices and weight status are believed to be influenced by various environmental factors such as easy availability of fast foods, increased

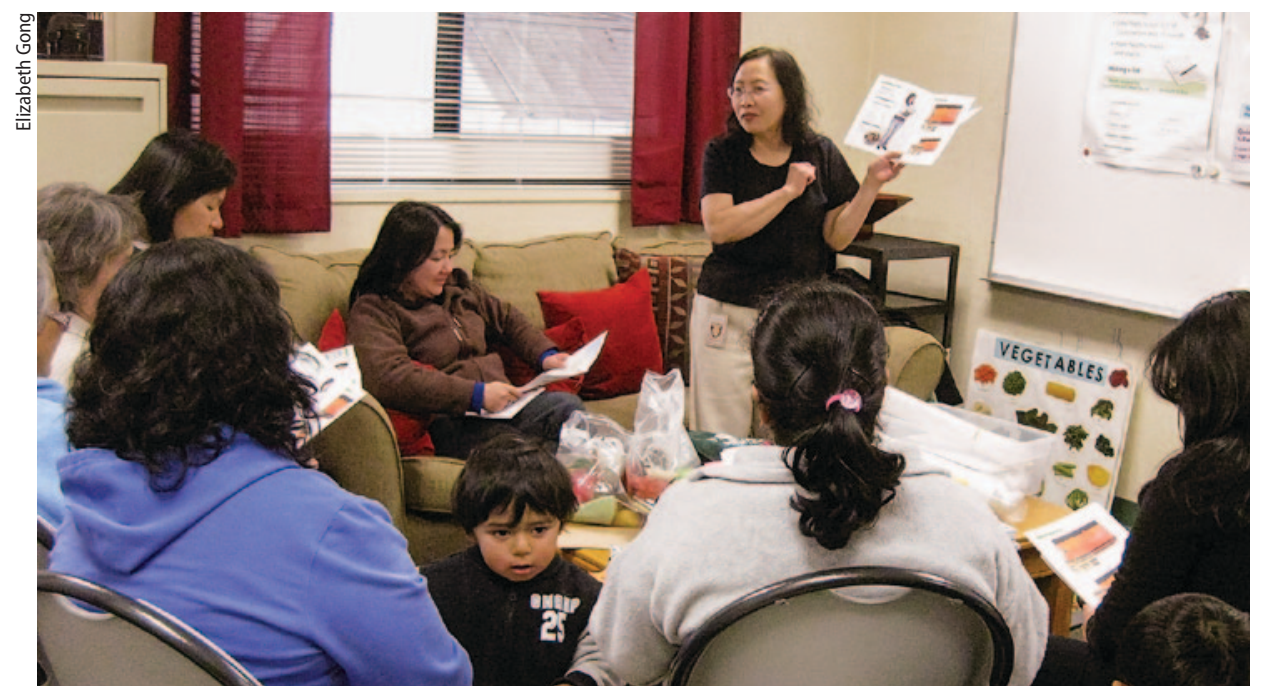

EFNEP educators such as Trinh Vo, above, deliver nutrition education programs to low-income families in Santa Clara County.

portion sizes, availability of soft drinks and unhealthy snack food on school campuses, reductions in physical activity programs and increases in sedentary activities, inadequate parks and recreational facilities, limited access to healthy foods and advertising of low-nutrient-dense foods to children and their families (Koplan et al. 2005).

Prevention strategies can reach whole communities and populations, and there is an increasing sense of urgency in mounting these strategies (Kumanyika et al. 2002; US Department of Health and Human Services 2001). For example, it has become increasingly clear that children's environments strongly influence their behaviors, and that meaningful and sustainable behavior change is unlikely to occur without support from the home, school and the larger community (Ritchie et al. 2006). Schools - where students spend a large proportion of their waking hours and where they eat one or two meals each weekday - are a prime area for changing the environment of children (Crawford et al. 2011). In addition, local communities can also be an effective arena for change and may be more responsive to new initiatives and more likely to achieve consensus than legislative and administrative bodies at higher levels of government. Further, obesity prevention policies that are adopted locally may also be implemented more widely (Khan et al. 2009).

\section{Effective prevention strategies}

Early obesity prevention strategies were relatively unsuccessful, focusing on educational tactics rather than combining education with broadly based community change designed to support lessons learned. In contrast, recent comprehensive school and community interventions are beginning to show decreases in children's body mass indices (BMIs) on a case by case basis (Economos et al. 2007; Foster et al. 2008; Hollar et al. 2010). Strategies to support healthy eating patterns in communities and neighborhoods have included zoning that limits fast food restaurants, improving restaurant menu offerings for children, locating supermarkets in "food deserts" and increasing the availability of farmers markets and community gardens (Larson et al. 2009; Lovasi et al. 2009; Zenk et al. 2009). Strategies to encourage physical activity have included establishing parks and bike paths and 
facilitating safe routes to schools (Parker et al. 2009).

Community-based intervention. Shape up Somerville, a comprehensive intervention undertaken in an ethnically diverse city of 77,000 near Boston, Massachusetts, united city and school officials and stakeholders to facilitate change in students' behavior patterns. A strong emphasis on school involvement was combined with changes in the broader community environment. Schools offered a new health curriculum as well as enhanced quality and quantity of healthful foods for students. In addition, the program encouraged walking to school with additional crossing guards and walking school buses, in which organized groups of students walk to school accompanied by one or more adults. Bike lanes and paths were improved, parks were renovated and sites were identified for new parks. Restaurants were encouraged to increase healthy options and/or alter portion sizes.

Documented improvements. Children's BMI z-scores were decreased by -0.1005 $(p<0.001)$ and the program demonstrated the effectiveness of broad-based community efforts to change the environment to one that is more supportive of behaviors that promote health and healthy weights (Economos et al. 2007). Examples of documented improvements included repainting crosswalks so people could see them better and hiring crossing guards, resulting in a $5 \%$ increase in children walking to school. In addition, schools featured more produce at breakfast and lunch, increasing their produce purchases from $\$ 90,000$ to $\$ 165,000$ (Berman and Russo 2007).

\section{Large community interventions}

California was the first state with private investments in large-scale, multisector community health initiatives designed to promote healthful eating and physical activity. Both the California Endowment's Healthy Eating, Active Communities (HEAC) Initiative and Kaiser Permanente's Healthy Eating Active Living (HEAL) campaign were initiated in the early part of this decade (2004 and 2005, respectively).

\section{Healthy Eating, Active Communities} (The California Endowment). The Healthy Eating, Active Communities (HEAC) Initiative created policy and environmental changes to increase children's access to healthy foods and physical activity (California Endowment 2005-2010). This initiative included six low-income communities - Baldwin Park, Chula Vista, Oakland, Santa Ana, South Shasta County, and South Los Angeles - with high rates of adult and childhood obesity. HEAC implemented programs and policies designed to increase healthy eating and physical activity in five environmental sectors: schools, after-school programs, neighborhoods, health care, and marketing and advertising.

Schools implemented state nutrition standards, increased physical education (PE) class time to meet state requirements, hired PE specialists, trained teachers in physical activity and involved parents in changing food and physical activity. After-school programs added physical activity and adopted SPARK, a research-based physical activity curriculum.

Parks were outfitted with updated equipment, and walking and biking were encouraged.

To encourage healthy eating habits, unhealthy snack foods were no longer prominently displayed at grocery stores near schools, and convenience stores near schools began selling produce and other healthier items. Finally, local physicians and promotoras (community workers who provide education and referrals) were trained in obesity prevention and policy advocacy, weight management programs were implemented, healthful hospital vending policies were developed, clinical practices were changed to include BMI charting and counseling, and obesity prevention messages were created.

One of the most important outcomes of the HEAC Initiative was the number of health-promoting policies adopted by participating schools and communities. Policies are critical to sustain change initiated in programs and activities. Across the six HEAC sites, about 250 policymakers and public officials were engaged in some way in developing or supporting health policy activities. Policies adopted by schools and communities participating in the HEAC Initiative include: school food marketing policies, school fundraiser policies, school food and physical activity policies, after-school wellness policies, after-school physical activity and food policies, neighborhood healthy vending policies, fast food moratoriums, health promotion in general plans, walkability policies and park space policies (Samuels 2010).

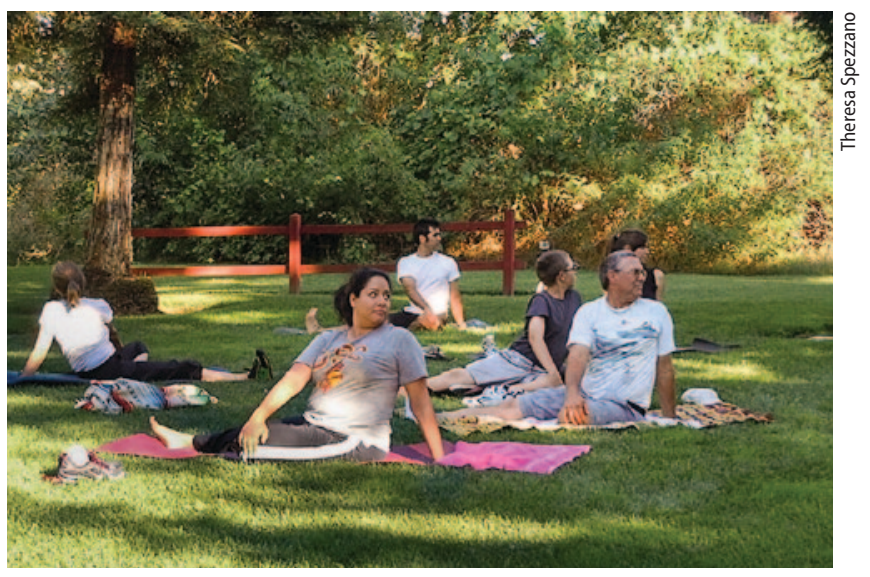

More than 330 community residents spent the summer biking, group exercising in the park and learning to eat better with Get Fit Riverbank, a program that was codeveloped by a UCCE advisor.
HEAC was one of the first comprehensive community interventions documenting that communities could take a comprehensive approach to improving food and physical activity opportunities for youth. The California Endowment believes that California's prosperity depends on the health of its population. To this end, the Endowment has initiated a 10-year multimillion-dollar initiative to advance policies and forge partnerships to build healthy communities in California.

Healthy Eating Active Living (Kaiser Permanente). Designed to reduce obesity by improving nutrition, boosting physical activity and supporting community and organizational policy and environmental changes, the Healthy Eating Active Living Community Health Initiative (HEAL$\mathrm{CHI}$ ) campaign was implemented in three low-income communities in Northern California - Modesto, Richmond and Santa Rosa. The HEAL program helped communities develop strategies for an action plan targeting four sectors: (1) schools (improving cafeteria options, nutrition education and physical education), (2) health care (incorporating BMI measures into well visits at community clinics 
and offering routine obesity counseling and referrals), (3) work sites (encouraging use of stairs and including physical activity and more healthful menu options in cafeterias) and (4) neighborhoods (building safe, lighted walking trails and establishing advocacy campaigns to increase healthy eating and physical activity options).

The HEAL-CHI campaign was successful in implementing sustainable policy and environmental strategies, with the most successful strategies identified as those that had an intense impact on more than $20 \%$ of the community population. In the three target communities, a total of 76 community health strategies were implemented, including 26 in organizational policy change, 19 at the program level, 14 in building community capacity, 12 in environmental change and five in public policy (Cheadle et al. 2012) (fig. 1). Strategies ranged from adding health elements to city general plans (policy) and improving school food offerings (environment), to cooking classes (programs) and training resident leaders (capacity building).

Significant population-level changes resulted from several high-dose strategies (fig. 2). Population dose includes both the strength of the intervention and the number reached. The highest-dose intervention activities were implemented in and around schools. For example, foods served at schools were modified and students' physical activity opportunities were enhanced.

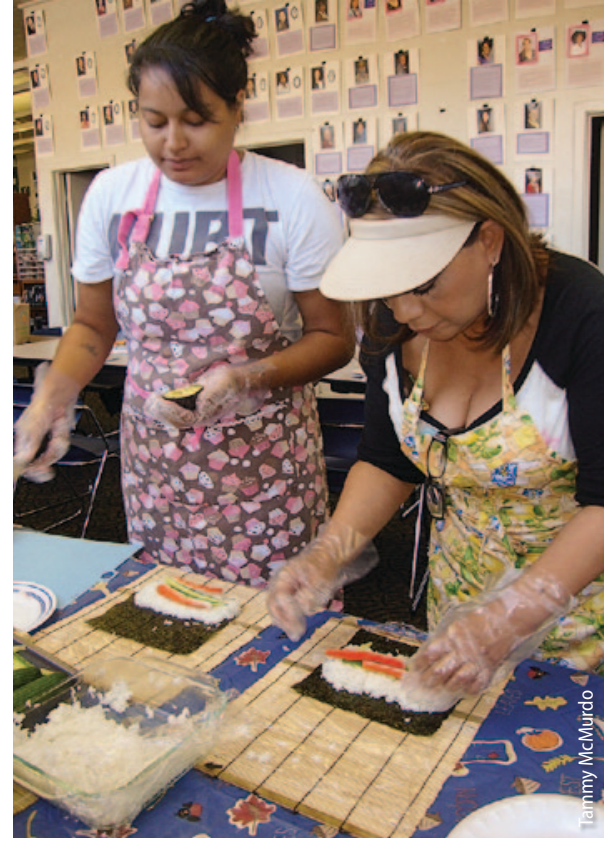

EFNEP participants practice safe food-handling skills learned during their nutrition class in Sacramento County.

Lessons that emerged from the HEAL$\mathrm{CHI}$ implementation can benefit other initiatives. These lessons include selecting intervention strategies of sufficient dose to have an adequate population reach and strength, focusing on specific subpopulations, and developing sensitive measures of impact, which can include behavioral measures of those directly exposed to community changes as well as intermediate measures of behavior change that may result in improvements in nutrition and physical activity. Kaiser Permanente has applied these findings to new HEAL-CHI communities in their Colorado, Northern California and Southern California regions and other Kaiser Permanente regions throughout the country.

\section{UCCE community coalitions}

Over a decade ago, UCCE nutrition specialists designed the first program in the country to train Cooperative Extension advisors to organize diverse, multisector community coalitions to promote community health (Ikeda et al. 2001). The purpose was to educate and empower coalitions to improve or create environments that foster healthy lifestyles for families and children at the local level. California counties implemented 13 of these projects, and the model has been used by numerous Cooperative Extension groups nationwide.

Spectrum of Prevention. The problem of pediatric overweight was addressed on multiple levels using the Spectrum of Prevention (fig. 3), an approach that has been applied successfully in a wide variety of initiatives, including violence prevention, injury prevention, traffic safety, nutrition, and fitness (Cohen and Smith 1999). The Spectrum identifies six levels of intervention that are complementary and, when taken together, can change the environment to promote healthy behaviors. By envisioning the individual within a rich and complex environment, the Spectrum's broad, multilevel approach to change provides a context within which individual change is most likely to occur.

The levels addressed by UCCE nutrition advisors ranged from educating individuals and providers to advocating for systemic and environmental change. The resulting programs were tailored to meet

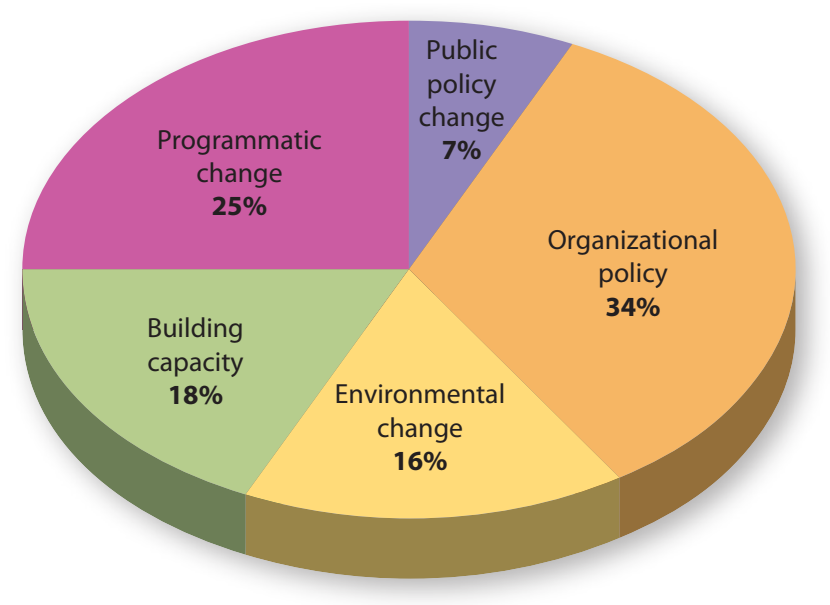

Fig. 1. Community change strategies by category and percentage of total effort applied in the HEAL study (Cheadle et al. 2012).

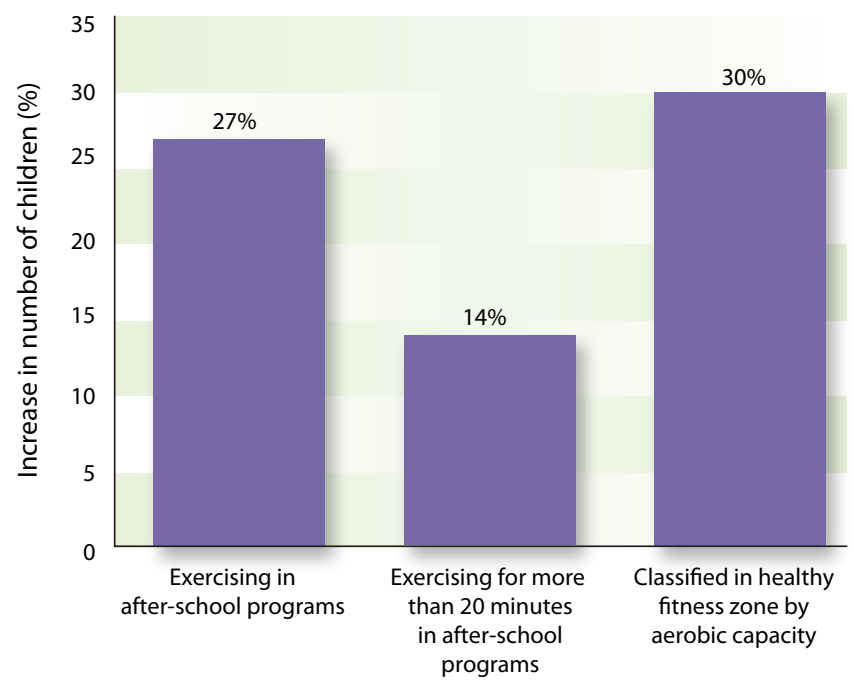

Fig. 2. High-dose community interventions with significant improvement $(p<0.05)$, as measured by percentage of children changing behavior in the HEAL program (Cheadle et al. 2012). 
the needs and priorities of the advisors' various communities and provide diverse models of promising practices for the promotion of health behaviors elsewhere in the state and nation.

\section{UCCE nutrition programs}

Two UCCE nutrition programs work with community agencies and schools to deliver nutrition education to lowincome families, adults and youth. These programs are the Expanded Food and Nutrition Education Program (EFNEP) and the UC CalFresh Nutrition Education Program (formerly known as the Food Stamp Nutrition Education Program). Historically, the programs have focused primarily on strengthening individual knowledge and skills (the first level of the Spectrum of Prevention) to change behaviors necessary for nutritionally sound diets.

Lessons emphasize appropriate portion sizes, label reading, meal planning, healthy choices, decreasing unhealthy fats, reducing sugar consumption and increasing physical activity and consumption of fruits, vegetables and whole grains. Although it was not the original intent of the program to prevent obesity, lesson topics link to nutrition factors that influence obesity. Measured outcomes have included increased consumption of fruits, vegetables, whole grains and low-fat dairy products as well as increased physical activity and improved budgeting skills (UC CalFresh 2011; UC EFNEP 2011).

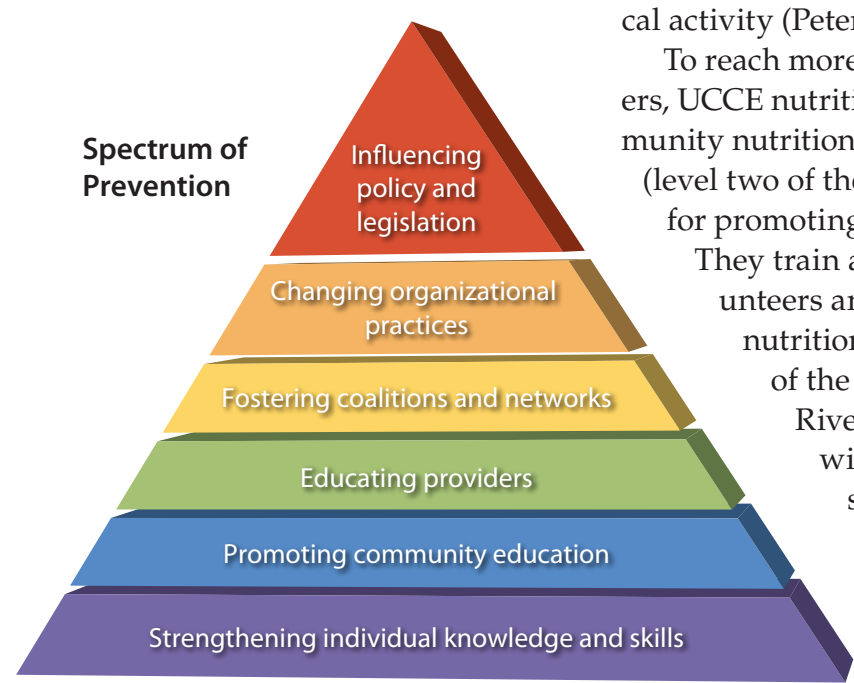

Fig. 3. The Spectrum of Prevention's multiple levels of intervention used together produce greater results than a single intervention activity (Cohen and Smith 1999).
Low-income, racial and ethnic groups. EFNEP and UC CalFresh educators reach out to underserved urban and rural community members. While poor nutrition and obesity cross all income levels, they are more prevalent in low-income and some racial and ethnic groups (Ogden and Carroll 2010; Ogden et al. 2010; Singh et al. 2010). Santa Clara UC CalFresh taught more than 500 Hispanic families with limited resources how to make the most of their grocery purchases nutritionally while saving money, and use saved dollars to purchase additional healthy foods. An inventory of the home food environment can demonstrate what families have available for healthy meals and snacks. The Santa Clara food inventory indicated that most families changed their home food environment after completing the classes: They increased fruit and vegetable variety by $30 \%$, the amount of fresh fruit by $30 \%$ and the use of whole wheat bread by $100 \%$ (Algert 2011).

For families starting new lives in the United States, it is easy to succumb to the high-fat, high-sugar eating habits and sedentary lifestyle that are common here. EFNEP educators in San Diego worked with Somali refugee parents by showing them how to plan, shop for and prepare healthy family meals on a limited budget. In addition, along with UC Davis researchers, EFNEP advisors developed and implemented curricula and DVD video teaching aids for Hmong families to encourage healthful nutrition practices. Hmong families showed improvements in food purchasing, water intake and physil activity (Peterson 2010) (table 1).

To reach more low-income consumers, UCCE nutrition staff promote commutrition efforts with partners

vel two of the Spectrum of Prevention oting nutrition education) nteers and providers to teach utrition education (level three of the Spectrum). UCCE in Riverside County partnered with nine middle and high schools to deliver the

EatFit program to more than 4,400 students. EatFit was developed by UCCE and UC Davis researchers to help teens analyze their own
TABLE 1. Hmong participants' self-reported improvements in nutrition practices after completing an EFNEP series of classes taught by Hmong educators with video clips and visuals $(n=166)$

Nutrition practice Improvement

\begin{tabular}{ll} 
Shopped for food on sale or with & $\%$ \\
$\begin{array}{l}\text { coupons } \\
\text { Planned meals/made a grocery list }\end{array}$ & 44 \\
$\begin{array}{l}\text { Increased physical activity } \\
\begin{array}{l}\text { Drank more water (rather than } \\
\text { sweetened beverages) }\end{array}\end{array}$ & 37 \\
\hline
\end{tabular}

TABLE 2. Average improvement in food consumption behaviors of middle and high school students participating in the EatFit nutrition program $(n=1,051)$

Food consumption

behavior

Improvement

Eat more fruits/vegetables

Eat less fast food/snack food

29.4

Drink less sweetened

35.2

beverages

diets and set personal eating and fitness goals. The EatFit curriculum was part of their physical education course work. A retrospective evaluation completed by nearly one-quarter of the students after the program showed increased consumption of fruits and vegetables and reduced consumption of fast foods, snacks and sweetened beverages (UC CalFresh 2011) (table 2).

Community partnerships. UCCE works with community partners to teach nutrition. UCCE Sacramento and San Joaquin partnered with First 5 to extend nutrition programming within their communities. First 5 is a California program that educates parents and caregivers about the important role they play in their children's development during the first five years. Sacramento Head Start and child-care providers received professional development training on the nutritional needs of preschool youth, a critical age for learning positive behaviors and trying new foods. Head Start is a USDA Health and Human Services program that provides education, health, nutrition and parent involvement services to low-income children and families. Parents served by five San Joaquin community-based agencies were 
trained to deliver nutrition education to children. Positive nutrition changes for preschoolers included trying new foods such as fish.

In addition, San Bernardino 4-H, EFNEP and the Master Gardener Program collaborated with the Norton Space and Aeronautics Academy on a gardening and nutrition project to provide youth with a Farm to Fork experience (Barnett et al. 2011). In Contra Costa County, UCCE is collaborating with two limited-income housing communities to promote healthy living with a goal of decreasing childhood obesity. Trained teen and adult volunteers deliver lessons to younger children, using hands-on activities to improve their nutrition, cooking, fitness and gardening skills (UC 4-H 2011).

Local coalitions and networks. UCCE nutrition advisors work closely with local coalitions and networks (level four of Spectrum of Prevention for promoting nutrition education). For example, a UCCE Stanislaus-Merced advisor codeveloped Get Fit Riverbank, a community-based 8-week nutrition and physical activity program designed to expose low-income families to inexpensive and fun ways to improve their health. More than 330 residents in the community united to spend the summer biking, walking and learning to eat better. Paired pre- and post-program clinical measurements showed that waistlines decreased an average of 2.3 inches, cholesterol levels dropped more than nine points and blood sugar levels dropped more than 10 points (Spezzano 2012) (fig. 4).

From 2010 to 2012, UCCE Fresno and UC Davis researchers partnered with the City of Fresno Parks and Recreation's Healthy Lifestyles Fitness Camp, using a family-centered teaching method in a summer day camp setting for low-income overweight youth. In 2011, Fitness Camp youth had lost weight $(-1.06$ kilograms in 9- to 11-year-olds and -1.58 kilograms in 12- to 17-year-olds), while control youth had gained weight $(+0.33$ kilogram), after accounting for baseline BMI for age $(p=0.04)$. A decrease in waist circumference was also significantly different between Fitness Camp and control groups, after controlling for baseline BMI $(p=0.003)$ (George et al. 2012).

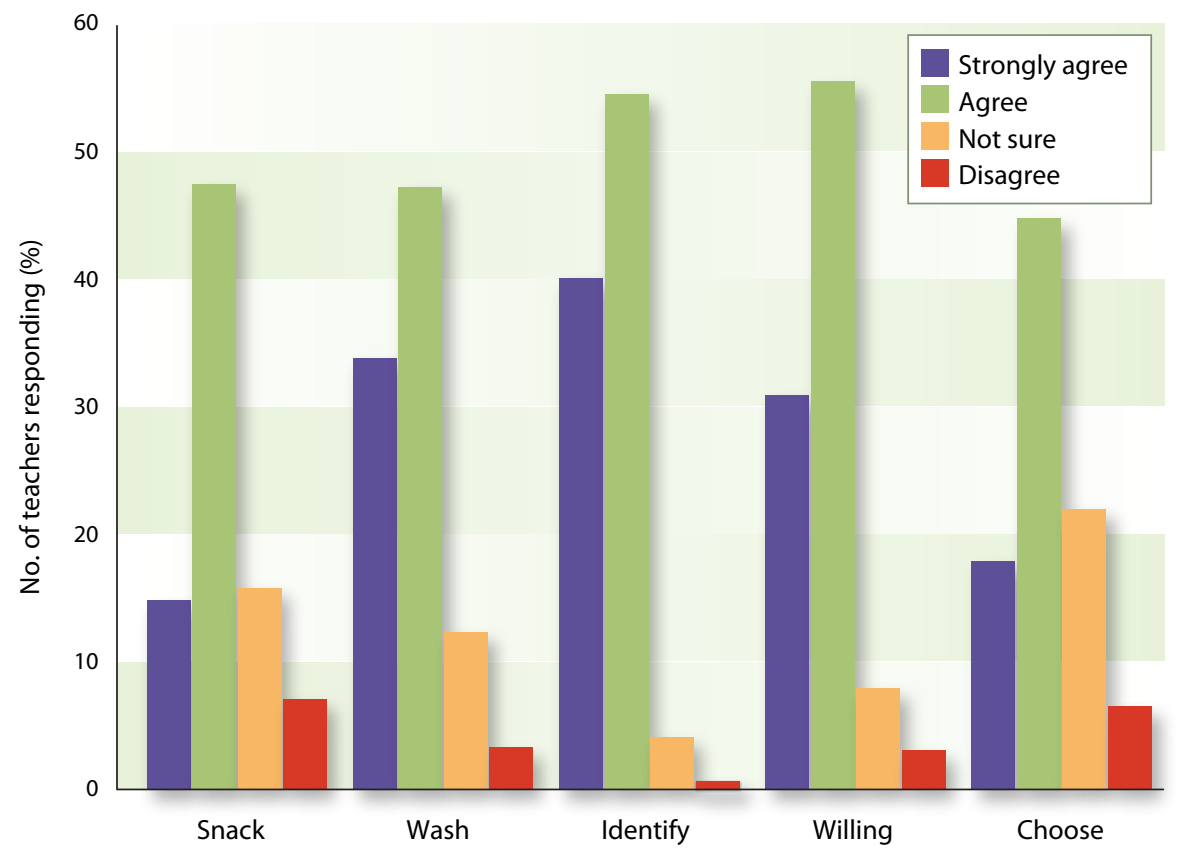

Fig. 5. After student participation in the CalFresh Nutrition Education Program, teachers reported improved student behaviors in the following areas: bringing fruit as a snack, washing hands often, identifying healthy food choices, willingness to try new foods at school, and choosing fruits or vegetables at school; $n=753$ teachers; 18,672 students. 2011 preliminary data shown.

Classroom nutrition education. UC CalFresh's evaluation task force members from the UC Davis campus, the UC CalFresh state office and UCCE developed the Teacher Observation Tool for use with UC curricula for preschool through sixth grade. The Teacher Observation Tool is a retrospective evaluation measuring teachers' perceptions and observations related to changes in students' foodrelated attitudes and behaviors as well as of the teachers' impact on the classroom nutritional health environment (level five of the Spectrum of Prevention). Teachers reported that after completing the UC CalFresh Nutrition Education Program, more students could identify healthy food choices and were more willing to try new foods than they had been at the beginning of the school year (fig. 5). In 2011, 753 teachers reported that 17,551 of 18,672 students improved their ability to identify healthy food choices, with mean scores increasing from $71 \%$ to $81 \%(p<0.0001)$ (Kaiser et al. In press).

\section{New obesity prevention program}

A new UCCE obesity prevention program will target children and their families in two California communities. This program is part of Healthy Families and Communities, an ANR strategic initiative that focuses on encouraging healthy lifestyles, boosting science literacy and fostering positive development among California's youth.

County-level UCCE advisors will lead this community-based program to change student attitudes, knowledge and behaviors in ways that are conducive 
to healthier dietary and physical activity patterns. In accordance with the evidence-based 2010 Dietary Guidelines for Americans (USDA DHHS 2010), the intervention will emphasize key obesity prevention messages: reducing consumption of sugar-sweetened beverages, limiting fast food and decreasing time spent in sedentary pursuits. These strategies have shown promise, as have statewide school policies targeting unhealthy foods and beverages, and both may be linked to the fact that the rising rate of childhood obesity is beginning to plateau in California (Sanchez-Vaznaugh et al. 2010). At the same time that the program discourages consumption of sugar-sweetened beverages and fast food, it will encourage increased consumption of fruits and vegetables.

The 2-year intervention will integrate multiple components: (1) nutrition education in classrooms, (2) work with teachers, administrators, food service staff and school wellness committees, (3) afterschool and summer programs, (4) youth engagement and empowerment using $4-\mathrm{H}$ strategies and (5) parent/family activities to influence the home environment. Outreach to local business and policy leaders will encourage their involvement in changing the community milieu to one that better supports children's healthful eating and activity behaviors, creating an environment conducive to child health.

Designed by UCCE specialists, nutrition advisors, and 4-H advisors, the intervention will demonstrate a comprehensive community-based approach to preventing child obesity at the local level. Strengthened by advisors' long-standing community ties, the new program will build upon lessons learned from Cooperative Extension specialists' work in this area, nutrition advisors' education programs and 4-H advisors' youth development expertise.

Intervention materials will be adapted from current Cooperative Extension resources. UCCE links with California's agricultural community will strengthen the intervention's ability to positively influence nutritional intakes and to create communitywide support for interventions that promote child health. Programs including UC CalFresh, Farm to School, and a variety of community coalitions will deliver consistent evidence-based obesity prevention messages. Peer leadership

will be a unique feature of the program, with 4-H youth serving as peer guides in school and after-school settings. In addition, the program will be continued during summertime activities for students. 4-H youth ambassadors will meet with community business and policy leaders to garner support for this health promotion effort.

UCCE links with California's agricultural community will serve to strengthen the team's ability to positively influence nutritional intakes and to create communitywide support for an intervention that promotes nutritional health and disease prevention for children.

\section{The current annual cost of obesity-related conditions in the United States is $\$ 147$ billion for direct medical care, and these costs are projected to double every decade...}

Programs in the past that have successfully impacted children's obesity rates have been both intensive and expensive. The new intervention will examine the potential of Cooperative Extension, with its existing community-based networks, to address this urgent societal problem in a cost-effective manner and to support positive community changes promoting the health and well-being of residents. The effectiveness of the program will be evaluated by comparing outcomes in the two targeted communities with those in comparison communities that do not receive the intervention.

The Institute of Medicine recently identified Cooperative Extension as a community leader well suited to guiding community interventions to prevent obesity (Glickman, Parker et al. 2012, 383). No other organizations have deep roots in communities throughout California and the country and longstanding involvement in youth programs and community nutrition programs. The confluence of these factors positions Cooperative Extension as a potential leader in the effort to solve one of the most critical health problems of our time: the epidemic of childhood obesity. If successful, the Healthy Families and Communities study will provide guidance to other California communities and Cooperative Extension affiliates, and will be a model of effective change in an area of critical importance to the state and nation.
The new program will be integrated with current nutritional approaches used by UCCE. UC CalFresh will be following the new SNAP-Ed guidelines to include an emphasis on obesity prevention in addition to nutrition education, at the same time permitting obesity outcome measures such as the body mass index (BMI). EFNEP will be following the 2010 Dietary Guidelines for Americans (USDA and DHHS 2010), which includes a community framework similar to the Spectrum of Prevention. Nutrition advisors can impact community health promotion and policy through education. Further, by aligning county nutrition programs with statewide goals and utilizing practices developed within county nutrition programs, statewide outcomes and impacts are likely to be more successful in addressing childhood obesity.

By targeting childhood obesity, Cooperative Extension commits energy and resources to a crucial health issue of our time. By providing leadership for the

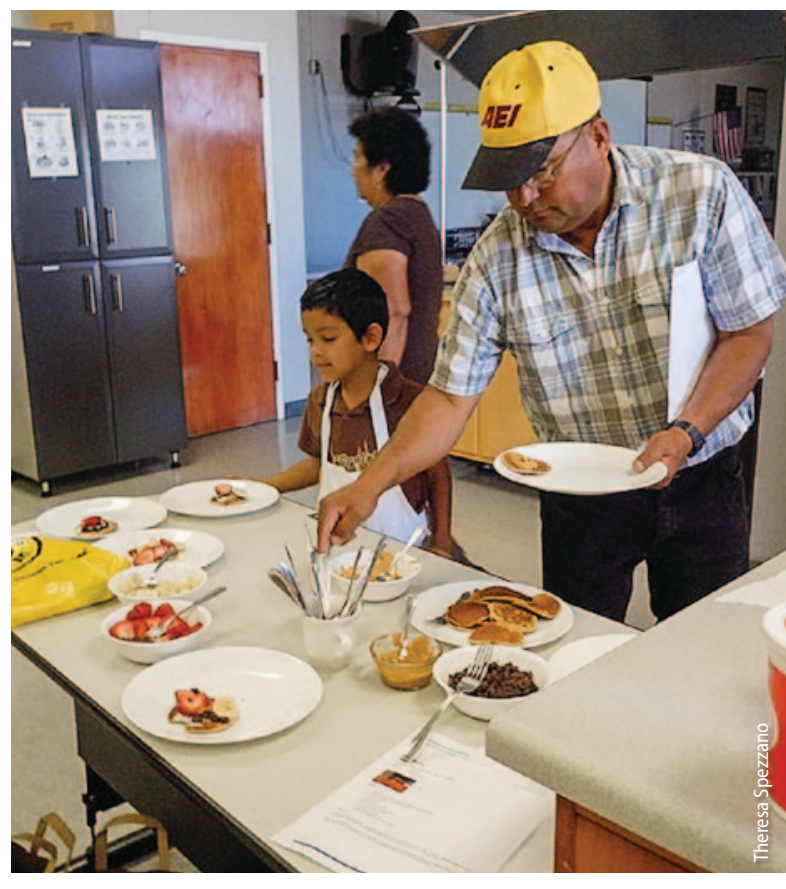

Participants in the 8-week Get Fit Riverbank program changed their nutrition and exercise habits, improving their weight, cholesterol level and blood sugar level. 
new Healthy Families and Communities obesity intervention, Cooperative

Extension will guide a community-based model that will inform future obesity prevention throughout the state. With its longstanding community ties, its experience in the areas of nutrition and $4-\mathrm{H}$ and its history of using research-based knowledge to improve people's lives, Cooperative Extension is poised to significantly improve the future health of California's population.
P.B. Crawford is Director, Atkins Center for Weight and Health, and Nutrition Specialist, Department of Nutrition Science and Toxicology, UC Berkeley; C.L. Schneider is Director, Youth, Families and Communities, UC ANR; A.C. Martin is Nutrition, Family, and Consumer Sciences Advisor, UCCE San Joaquin County; T. Spezzano is Nutrition, Family, and Consumer Sciences Advisor, UCCE Stanislaus and Merced counties; S. Algert is Nutrition, Family, and Consumer Sciences Advisor, UCCE Santa Clara County; C. Ganthavorn is Nutrition, Family, and Consumer Sciences Advisor, UCCE Riverside County; Y. Nicholson is Nutrition, Family, and
Consumer Sciences Advisor, UCCE Sacramento County; M. Neelon is Nutrition, Family, and Consumer Sciences Advisor, UCCE Contra Costa County; P.C. Wooten Swanson is Nutrition, Family, and Consumer Sciences Advisor, UCCE San Diego County; and S. Donohue is Nutrition, Family, and Consumer Sciences Advisor, UCCE Butte County.

EFNEP is funded by USDA through the National Institute of Food and Agriculture. UC CalFresh Nutrition Education Program is funded through a joint agreement among the USDA Food and Nutrition Services, the California Department of Social Services CalFresh Branch and UCCE.

\section{References}

Algert S. 2011. UC CalFresh improves the home food environment of low-income Hispanic families. UC ANR UC Delivers. http://ucanr.org/delivers/?impact=873\&de livers $=1$.

Barnett C, Hartin J, Wilshire C. 2011. 4-H, Master Gardeners, and EFNEP collaborate on school project. UCANR. UC Delivers. http://ucanr.org/delivers/?impact=816\&de livers $=1$

Berenson GS. 2005. Obesity - A critical issue in preventative cardiology: The Bogalusa Heart Study. Prev Cardiol 8(4):234-41.

Berman J, Russo K. 2007. 'Shape Up Somerville' Has Students Trading Soft Drinks for Salads. Nightline, ABC News, June 22. http://abcnews.go.com/Nightline/story?id=3 306253\&page $=1$ \&singlePage $=$ true\#.UOeiMLbqEv4 (accessed Dec. 19, 2012).

California Endowment. 2005-2010. The California Endowment's Healthy Eating, Active Communities Initiative. www.calendow.org/article.aspx?id=1516\&ltemID $=1516$ (accessed April 1, 2012).

Cheadle A, Rauzon S, Spring R, et al. 2012. Kaiser Permanente's Community Health Initiative in Northern California: Evaluation findings and lessons learned. Am J Health Promot 27(2)e59-68.

Cohen L, Smith S. 1999. The spectrum of prevention: Developing a comprehensive approach to injury prevention. Injury Prev 5(3):203-7.

Crawford PB, Gosliner W, Kayman H. 2011. The ethical basis for promoting nutritional health in public schools in the United States. Prev Chron Dis 8(5):A95.

Cubbin C, Pedregon V, Egerter S, Braveman P. 2008. Where we live matters for our health: The links between housing and health. Robert Wood Johnson Foundation Issue Brief 3: Neighborhoods and Health.

Economos CD, Hyatt RR, Goldberg JP, et al. 2007. A community intervention reduces BMI z-score in children: Shape up Somerville first year results. Obesity 15(5):1325-36.

Finkelstein EA, Trogdon JG, Cohen JW, Dietz W. 2009. Annual medical spending attributable to obesity: Payer- and service-specific estimates. Health Aff 28(5):822-31.

Fisberg M, Baur L, Chen W, et al. 2004. Obesity in children and adolescents: Working group report of the second World Congress of Pediatric Gastroenterology, Hepatology, and Nutrition. J Pediatr Gastroenterol Nutr 39 (Suppl 2):S678-87

Foster GD, Sherman S, Borradaile KE, et al. 2008. A policybased school intervention to prevent overweight and obesity. Pediatrics 121(4):e794-802.

George G, Schneider C, Ginsburg G, et al. 2012. Summer camp promotes anthropometric changes in overweight youth in Fresno, California. FASEB J [Abstract].

Glickman D, Leavitt M, Shalala D, Veneman A. 2012

Lots to Lose: How America's Health and Obesity Crisis

Threatens Our Economic Future. Bipartisan Policy Center. http://bipartisanpolicy.org/projects/lotstolose (accessed August 20, 2012)
Glickman D, Parker L, Sim L, et al. (eds.). 2012. Accelerating Progress in Obesity Prevention Solving the Weight of the Nation. IOM. Washington, DC: National Academies Press. Hollar D, Lombardo M, Lopez-Mitnik G, et al. 2010. Effective multi-level, multi-sector, school-based obesity prevention programming improves weight, blood pressure, and academic performance, especially among low-income, minority children. J Health Care Poor Underserved 21(2):93-108

Ikeda J, Mitchell R, Crawford PB. 2001. Children and Weight: What Communities Can Do. UC ANR Pub 3422 Oakland, CA.

Kaiser LL, Schneider CS, Neelon M, et al. In press. Evaluation of nutrition outcomes in youth: Challenges and opportunities. In: Trejos E (ed.). Youth:Practices, Perspectives and Challenges. NY: NOVA Science Publishers.

Khan LK, Sobush MS, Keener D, et al. 2009. Recommended community strategies and measurements to prevent obesity in the United States. Morbidity Mortality Weekly Rep 58(RR07):1-26.

Koplan JP, Liverman CT, Kraak VI (eds.). 2005. Preventing Childhood Obesity: Health in the Balance. IOM. Washington, DC: National Academies Press.

Kumanyika S, Jeffery RW, Morabia A, et al. 2002. Obesity prevention: The case for action. Int J Obes 26(3):425-36. Larson NI, Story MT, Nelson MC. 2009. Neighborhood environments: Disparities in access to healthy foods in the U.S. Am J Prev Med 36(1)

Lovasi GS, Hutson MA, Guerra M, Neckerman M. 2009 Built environments and obesity in disadvantaged populations. Epidemiol Rev 31:7-20.

Madsen KA, Weedn AE, Crawford PB. 2010. Disparities in peaks, plateaus and declines in prevalence of high BMI among adolescents. Pediatrics 126(3):434-42.

Ogden CL, Carroll MD. 2010. Prevalence of Obesity Among Children and Adolescents: United States, Trends 1963-1965 through 2007-2008. www.cdc.gov/nchs/data/ hestat/obesity_child_07_08/obesity_child_07_08.htm.

Ogden CL, Carroll MD, Kit MD, Flegal KM. 2012.

Prevalence of Obesity in the United States, 2009-2010. CDC, NCHS Data Brief No. 82

Ogden CL, Lamb MM, Carroll MD, Flegal KM. 2010. Obesity and Socioeconomic Status in Adults: United States, 2005-2008. NCHS Data Brief 50. www.cdc.gov/ nchs/data/databriefs/db50.pdf

Olshansky SJ, Passaro DJ, Hershow RC, et al. 2005. A potential decline in life expectancy in the United States in the 21st century. N Engl J Med 352(11):1138-45.

Parker L, Burns AC, Sanchez E (eds.). 2009. Local Government Actions to Prevent Childhood Obesity. IOM. Washing ton, DC: National Academies Press.

Peterson L. 2010. UC creates nutrition education videos to reach diverse, low-literacy communities. UC ANR. UC Delivers. http://ucanr.org/delivers/?impact=808\&deliv ers $=1$.
Quinlan A, Lieberman D, Ferguson G. 2010. American Voters Support Investment in Preventing Childhood Obesity. Greenberg Quinlan Rosner Research and American Viewpoint. Washington, DC

Ritchie LD, Crawford PB, Hoelscher DM, Sothern MS. 2006 Position of the American Dietetic Association: Individual-, family-, school-, and community-based interventions for pediatric overweight. J Am Diet Assoc 106(6):925-45.

Samuels SE, Craypo L, Boyle M, et al. 2010. California Endowment's Healthy Eating, Active Communities program: A midpoint review. Am J Public Health 100(1 1):2114-23.

Sanchez-Vaznaugh EV, Sanchez BN, Baek J, Crawford PB. 2010. Competitive food and beverage policies: Are they influencing childhood overweight trends? Health Aff 126(3):434-42.

Singh GK, Siahpush M, Kogan MD. 2010. Rising social inequalities in US childhood obesity, 2001-2007. Ann Epidemiol 20(1):40-52

Spezzano T. 2012. Get Fit Riverbank: A Community in ACtion. UC ANR. UC Delivers. http://ucanr.org/delivers/?imp act $=870 \&$ delivers $=1$.

Swinburn B, Gill T, Kumanyika S. 2005. Obesity prevention: A proposed framework for translating evidence into action. Obes Rev 6(1):23-33.

UC 4-H. 2011. UC ANR 4-H Healthy Living CYFAR Project www.ca4h.org/Projects/HealthyLiving/CYFARII/ (accessed August 20, 2012).

UC CalFresh. 2011. UC CalFresh Nutrition Education Program Fiscal Year 2011 Final Report. www.uccalfresh.com/ Final\%20Report\%20without\%20County\%20Attachs\%20 FFY2011.pdf (accessed July 31, 2012).

UC EFNEP. 2011. UC ANR Impact Report Fiscal Year 2010-2011. http://ucanr.org/sites/EFNEP_CA/Impact/ (accessed July 30, 2012)

[USDA DHHS] US Department of Agriculture and US Department of Health and Human Services. 2010. Dietary Guidelines for Americans, 2010 (7th ed.). US Government Printing Office, Washington, DC

US Department of Health and Human Services. 2001. The Surgeon General's Call to Action to Prevent and Decrease Overweight and Obesity. US DHHS, Public Health Service, Office of the Surgeon General. Washington.

Wang Y, Beydoun MA, Liang L, et al. 2008. Will all Americans become overweight or obese? Estimating the progression and cost of the US obesity epidemic. Obesity 16(10):2323-30.

Zametkin AJ, Zoon CK, Klein HW, Munson S. 2004. Psychiatric aspects of child and adolescent obesity: A review of the past 10 years. FOCUS. 2:625-41.

Zenk SN, Lachance LL, Schulz AJ, et al. 2009. Neighborhood retail food environment and fruit and vegetable intake in a multiethnic urban population. Am J Health Promot 23(4):255-64. 